\title{
Affective representation and affective attitudes
}

\author{
Jonathan Mitchell ${ }^{1,2}$
}

Received: 12 December 2018 / Accepted: 13 June 2019 / Published online: 21 June 2019

(c) The Author(s) 2019

\begin{abstract}
Many philosophers have understood the representational dimension of affective states along the model of perceptual experiences. This paper argues affective experiences involve a kind of personal level affective representation disanalogous from the representational character of perceptual experiences. The positive thesis is that affective representation is a non-transparent, non-sensory form of evaluative representation, whereby a felt valenced attitude represents the object of the experience as minimally good or bad, and one experiences that evaluative standing as having the power to causally motivate the relevant attitude. I show how this view can make sense of distinctive features of affective experiences, such as their valence and connection to value in a way which moves beyond current evaluativist views of affect.
\end{abstract}

Keywords Affective $\cdot$ Representation $\cdot$ Consciousness $\cdot$ Attitude $\cdot$ Perception

\section{Introduction. Affect, representation, and value}

There are a range of occurrent mental states or experiences which philosophy and psychology classify as affective. Included in this category are pains, pleasures, moods, and emotions. One puzzling issue is whether affective experiences are merely nonintentional raw feels or representational states which present seemingly objective, truth-evaluable, states of affairs. One may also worry about the rationale for the categorization; what does an episode of fear share with a searing headache, or an anxious mood with an orgasm?

This article argues that paradigmatic affective experiences are (at least partly) constituted by a kind of personal level representation called affective representation. The personal level caveat distinguishes the phenomenological account provided here from

\footnotetext{
$凶$ Jonathan Mitchell

jonathan.mitchell@manchester.ac.uk

1 University of Manchester, Manchester, UK

2 Kenilworth, UK
} 
functional or computational accounts, which are framed at the subpersonal level. ${ }^{1}$ This is not to deny there is an important connection between accounts of affect at the personal and subpersonal levels, and that the former should be sensitive to issues of how affect is processed at the latter level, however, my focus here is on what Daniel Dennett calls 'the explanatory level of people and their sensations and activities'. ${ }^{2}$ One answer to the categorization problem would, therefore, be incomplete-namely, that affective states are underwritten by the same neurophysiological states or subpersonal systems (e.g. in terms of 'core affect'). ${ }^{3}$ We also require a personal level explanation which justifies the categorization at the level of affective experience.

My focus is, therefore, on affective representation in phenomenally conscious experiences. I develop a theory that elucidates the distinctive nature of affective representation, which departs from what I call perceptualism about affective consciousness (perceptualism hereafter). I argue that the modelling of affective representation on perceptual representation, while instructive up to a point, occludes features of the former that are disanalogous from the latter. My positive thesis is that affective representation is a non-transparent, non-sensory, form of evaluative representation. This involves a distinctive intentional structure, whereby a felt valenced attitude (the 'vehicle') represents the intentional object of the experience as minimally good or bad (the content), and one experiences that evaluative standing as having the power to casually motivate the relevant affective attitude. I call this the affective attitude theory (AAT hereafter).

A key dimension to AAT is a distinction between vehicles (i.e. representations)—what Ned Block calls 'mental paint', and so the component that does the representing - and intentional content (i.e. what such experiences represent). ${ }^{4}$ AAT explains how this distinction applies to affective experiences. Further to this, while there are significant differences between pains, pleasures, moods, and emotions, AAT specifies the 'representational genus' of which these types are species, providing one rationale for categorizing the relevant states as affective. In sum, the goal is to provide an outline for a theory of affective representation which reflects the distinctive characteristics of affective experience, as a starting point for theorizing about them.

Let me now note two important preliminary issues. First, one might question the motivation behind providing a theory which offers a unitary account of affect, as focusing on the category of affective experience in general, rather than, for example, just emotion or pain. It might be suggested that while affective states are paradigmatically valenced or tied to motivation, nonetheless one's theory of pain and pleasure is likely to depart from one's theory of emotion and mood (and the former should not constrain the latter). ${ }^{5}$ In response, it bears emphasizing that nothing offered here prevents one from going on to develop theories of specific affective states which highlight significant

\footnotetext{
1 For the distinction between the personal and subpersonal see Dennett (1969).

2 Dennett (1969: p. 93).

3 See Russell and Barrett (1999: pp. 805-19).

4 See Block (1996: pp. 19-49).

5 This might seem unsurprising given that the physical realizers of these states are distinct (i.e. for pain there are dedicated nociceptors; for emotions, putative affective quasi-modules of the brain). However, such differences should not undermine providing a unitary account of affect understood in terms of personal level experiences, which may share some fundamental characteristics. I thank an anonymous referee at Synthese for pressing this issue.
} 
differences between them. In that sense, the project is similar to attempts to explicate what is shared by sense-perceptual experiences. We recognize categorical differences between vision, audition, gustation, etc., but at the same time highlight fundamental shared features or roles, which legitimates talk of sense-perceptual experiences per se. The hope, therefore, is that the designation 'affective' is not an arbitrary linguistic artefact-lumping together states which are not inherently similar-but reflects something fundamentally similar about emotions, moods, pains, and pleasures, such that there is justification for classifying them together. AAT will provide a philosophical rationale for this pre-theoretical categorization by appealing to a distinctive kind of affective representation which is broadly applicable to them all.

Connected to the above, let me say something about the intentionality of affect. The main views that AAT will be set in opposition to-perceptualism and forms of evaluativism about affect - accept that affective experience is in some sense intentional. So, to be critically engaged with such views, shared assumptions are required. However, it bears emphasizing that the arguments here will primarily concern the paradigm cases of purported affective intentional experiences, namely emotions and pains. Although, I will have something to say on the intentionality of moods, and if we accept the intentionality of pains then we should also accept the intentionality of pleasures. Nonetheless, if one is resistant to the claim that particular types of affective experiences are intentional, then AAT is still philosophically instructive for seeing how one might develop a view which frames affectivity in terms of a distinctive kind of intentionality. ${ }^{6}$

The roadmap is as follows. Section 2 explains the motivation for perceptualism by framing it as a response to separatist views in philosophy of mind, emphasizing the connection between representation and phenomenality. Section 3 first considers analogies between perceptual and affective experience which support perceptualism. However, disanalogies are then considered which—pace perceptualism - are suggestive of a type of representation distinctive to affective experiences. Section 4 outlines AAT, which specifies affective attitudes as the representational vehicle of affective experience, explaining how such attitudes relate to their evaluative content. It also compares AAT with existing forms of evaluativism about affect, including the views of Robert Roberts, Peter Carruthers, and Bennet Helm, and argues that AAT is in certain respects preferable.

\section{Separatism and perceptualism}

To understand the motivation for perceptualism it helps to consider separatism in philosophy of mind. Some theories of mind make a categorical distinction between intentional and phenomenal states. ${ }^{7}$ On the one hand, we have intentional states, paradigmatically beliefs and desires, which arguably have no inherent what-it-islikeness. On the other hand, we have inherently phenomenal states, which are (again arguably) non-representational, such as bodily sensations, pains, itches, tickles, orgasms, and more controversially moods and (aspects of) emotions. As Terance

\footnotetext{
6 I thank an anonymous referee at Synthese for pressing me on these points.

7 See Block (1995: pp. 227-87) and Nelkin (1989: pp. 129-41).
} 
Horgan and John Tienson put it: 'we can call this picture separatism because it treats phenomenal aspects of mentality and intentional aspects of mentality as mutually independent, and thus separable' ${ }^{8}$ Hence neither intentional nor phenomenal states are reducible to each other, although they are not mutually incompatible (as in complex states which include both phenomenal and intentional states or components). On the basis of this distinction, the project of naturalizing intentionality can be pursued separately from the hard problems of phenomenal consciousness. ${ }^{9}$ Intentional states, will not require for their realization, or our understanding of their intentionality, any necessary reference to phenomenal states. ${ }^{10}$

Regardless of the success of naturalizing intentionality in this way, some philosophers have also attempted to naturalize phenomenal consciousness. This begins by rejecting separatism: it is claimed that on the right analysis many of the mental states that inherently have phenomenal character have intentional content, and so are representational.

One aspect of this project is providing representational accounts of personal level affective states, for example, an episode of fear, or a headache. With this in mind, representationalists have turned to sense-perceptual experiences as paradigmatic, since their intentionality and phenomenological are importantly connected. ${ }^{11}$ One central aspect of this connection, emphasized by representationalist and intentionalist views, is that it is in virtue of representing the sense-perceptible (phenomenal) properties it does (e.g. colour, shape, and movement)—and so in having the intentional content it does-that sense-perceptual experience has (in significant part) the phenomenal character it does. On strong representationalist views phenomenal character is entirely determined by intentional content; once we specify the representational content of any mental state, there is no phenomenal remainder or unanalysable quale left over. ${ }^{12}$ Note though, even for weaker varieties of intentionalism not committed to the strong representationalist claims that (1) representational content exhausts phenomenal character, or (2) externalist psychosemantics, where what an intentional state represents is determined by environmentally specified tracking relations (e.g. reliable causal co-variance), this strategy has been pursued. ${ }^{13}$

So, the broad strategy is to provide representational analyses of affective experiences by modelling their intentionality on perceptual experiences. The properties affective experiences represent will, however, be different from the standard fare of colour, shape, and movement; evaluative properties are suggested, for example, the dangerousness of an animal in the case of occurrent fear, the badness-for-one of an (extra-mental) bodily state in the case of a headache. Nonetheless, such experiences are sufficiently perception-like qua their intentional nature to lend themselves to perceptualist treatments which point to significant analogies with perceptual experiences.

\footnotetext{
8 Horgan and Tienson (2002: p. 520).

9 See Chalmers (1996: Ch. 1).

10 See Fodor (1975) and Dennett (1969: Ch. 2 and Ch. 4).

11 Cf. Relationalist views (e.g. Campbell 2002).

12 See Harman (1990: pp. 31-52), Tye (1995) and Lycan (1996).

13 For example, see Mark Johnston who claims affect is a sensuous disclosure of value (Johnston 2001: pp. 181-214). Perceptualist accounts of affective states are also popular with early phenomenological thinkers (see Scheler 1973 and Sartre 2003; see Poellner 2016: pp. 1-28 for discussion).
} 
Prevalent in this vein are various perceptualist, and evaluative perceptualist, theories of emotions and pains. For example, Michael Tye, Brian Cutter, and David Bain appeal to the 'perceptuality' of pains in their evaluativist accounts of unpleasant pains, ${ }^{14}$ and Christine Tappolet appeals to analogies with perceptual experiences to motivate her perceptualist view of emotional experiences as (non-conceptual) evaluative representations. $^{15}$

Let me further clarify the strategy: in contrast to separatism, we should recognize the intentionality which is characteristic of states of phenomenal consciousness, and we can provide representationalist accounts of affective experiences by modelling their intentionality (and what follows from it) on that of perception. I label this (broad) perception-based model of affective experience perceptualism. Importantly, the claim is not that affective experiences literally are sense-perceptual experiences (e.g. that affect is a kind of seeing). Neither is perceptualism committed to the implausible claim that affective and sense-perceptual experiences need to be alike in all respects- they won't be given they are different kinds of experiences (which represent different kinds of properties). Rather, perceptualism makes the claim that affective experiences qualify as perceptual given the nature of their intentionality. More precisely, they will qualify as perceptual if they are analogous in important ways to perceptual experiences qua their representational character (and what follows from it), where the paradigm case is senseperceptual experience. Given this, if there emerge significant disanalogies between the intentional nature of affective and perceptual experience (or disanalogies which point toward this) then this will undermine the view. Or, at least such considerations would motivate considering an account of affective representation as a kind of representation distinctive to affective experience (see Sect. 4). ${ }^{16}$

As a final point on this issue, if talk of affective experience being perceptual merely conveys that affective states can be intentional experiences (in some non-committal way) then I have no quarrel with that. However, I take it that the minimal commitment of perceptualism is that of modelling the intentional nature of affective experience on perceptual experience. And if affective representation (as capturing the intentional nature of affective experience) turns out to be substantively different from paradigmatic perceptual representation then the resulting view will not be a form of perceptualism as I am understanding it here.

\section{Sense-perceptual and affective experiences}

\subsection{Candidate cases}

To assess perceptualism, it helps to chart analogies and disanalogies between relevant experiences. Let me, however, note important caveats. The discussion of purported

\footnotetext{
14 On pains as perceptual states see Pitcher (1970), Hill (2006: pp. 75-98, 2009). See Tye and Cutter (2011: pp. 90-109), Bain (2017: 462-90), for evaluative perceptualism about pains.

15 For emotions one should distinguish between neo-Jamesian accounts-where the perception is of bodily states (see Prinz 2004; Barlassina and Newen 2014: pp. 637-78) - and those where the perceptual experience is directed toward evaluative properties of particular objects (see Tappolet 2016: Ch. 1; Tye 2008: pp. 25-50; de Sousa 1987: Ch. 6; Roberts 2003).

16 I thank an anonymous referee at Synthese for pressing me on these points.
} 
analogies (and disanalogies) will be between sense-perceptual and affective experiences, where both are framed as occurrent episodic states, rather than as dispositional states. This is not to suggest that there are not important things to be said about affective states as dispositions, but this will not be my focus here. Further to this, the main cases that will be discussed are two particular kinds of affective experiences, namely a specific emotional episode and a pain experience. However, in the course of the discussion I also discuss a mood experience (again where the latter is understood as an occurrent state).

With these caveats borne in mind, let's start with a paradigmatic sense-perception, namely a visual perceptual experience:

VPE (visual perceptual experience): I am sitting in my office, at my desk, looking out of the window onto the courtyard. As I do so I see a number of discrete things, but first and foremost there is a full visual scene, including the blue hue of the sky, the greens and reds of various trees and shrubs, and the purple of the rectangular sign which, in large type, reads 'Economics'. This full visual scene is complex, and it is difficult to take in all the features simultaneously. As I continue to peer out, my attention is drawn in various directions; the motion of the walking students often, without deliberate effort, captures my attention, at least for as long as they appear in the scene since they quickly disappear out of it. Then again, without effort, my attention is drawn to the purple Economics sign. 'That's certainly purple', I think, and then I turn back to my laptop.

The description is a pre-theoretical report-without technical terms. Let's try something similar for affective experience, namely a paradigmatic emotional experience:

EE (emotional experience): I am in a zoo, looking at a gorilla grimly loping from left to right in its cage, which seems safely behind bars. Then I see the door to the cage has been left wide open and I am suddenly overcome with fear. My attention is immediately directed toward the gorilla, and its movements, looking to see how close it is to the open door. There is a palpable feeling of the situation now being dangerous in a way it was not before, and that something has definitively changed. The gorilla's physical presence affects me. As it moves further toward the door my posture is tense, and I take a few careful steps backward, preparing to run. Finally, the zookeeper rushes in, slams the door shut, and bolts it; 'that was a close one!' I say. ${ }^{17}$

Again, this description is a pre-theoretical report without technical terms. Finally, here is something similar for a pain experience:

PE (pain experience): I am walking around my house, absent-mindedly chatting. Absorbed in conversation I fail to notice the open cupboard door behind me. As I go to pick up a bit of rubbish off the floor and rise back up, I bang my head on the door. At this moment, there is an immediate and profoundly unpleasant searing sensation on the back of my head where I smacked it. I rub my hand against my head at the spot where I hit it, wincing as I do so. The pain continues for

17 This is a modification of an example from Goldie (2000). 
30 seconds or so, and then the intensity begins to drop off. After responding to various questions of 'are you ok', with 'yes, I'm fine', I return to the conversation.

With these examples in mind, let's specify analogies.

\subsection{Analogies}

(A1) The states are present to phenomenal consciousness. VPE, EE, and PE have an overall phenomenal character, there is 'something-it-is-like' to have these experiences. Moreover, there is not just 'something-it-is-like' in general to have these experiences, but more specifically the relevant 'what-it-is-likeness' is a 'what-it-is-likeness' for $\mathrm{me}$, as the one undergoing them. Put otherwise, there is an ineliminable first-person perspective. ${ }^{18}$ It may seem trivial to point out that these experiences are phenomenally consciousness in this way, yet keeping this in mind is important since further claims depend on this.

(A2) The states are about something and so exhibit a minimal form of intentional experiential content. VPE, EE, and PE possess what I will call intentional experiential content. We can frame experiential intentional content in terms of how things seem to the subject, that is how the object of the experience manifestly is for the subject (the object presented, as it is presented). What do they present in this way? In one sense in VPE it is the full visual scene and in EE and PE the full affective situation. Yet, for simplicities sake, we can focus on objects of attention: part of what VPE presents is the Economics sign; part of what EE presents is the gorilla; part of what PE presents is the (non-mental) bodily state located at the back of my head. ${ }^{19}$ Talk of a minimal form of intentional experiential content signals that we need not yet commit to the claim that experiences have propositional content, or involve the deployment of specific conceptual capacities; those are substantive claims for which we need further arguments.

Let me now consider a specific objection to (A2) being true of the class of affective experiences. Moods, whilst affective states, don't plausibly have intentional content-they aren't about anything. ${ }^{20}$ However, consider the following description of joy:

When I woke up this morning I felt like smiling...I'm completely free from worry...I' $m$ in tune with the world...the world seems basically good and beautiful...there is an inner warm glow, a radiant sensation...I'm at peace with the world...there's a particularly acute awareness of pleasurable things, their sounds, their colours, and textures - everything seems more beautiful, natural...there is

\footnotetext{
18 Tye (1995: p. 12) calls this perspectival subjectivity.

19 For more on the intentionality of pain see Bain (2003: pp. 502-23). Note though that the pain experience (on this view) is a first-order intentional experience, and so is not 'experience directed' but is directed towards non-mental bodily states (see Sect. 4 for more on this). NB: Whiting (2009: pp. 281-303) is a dissenting voice against emotions having intentional content. Although this is a minority view in theory of emotion since most theorists think that emotions have intentional content in some sense.

20 See Deonna and Teroni 2012: p. 4; de Sousa 1987: pp. 7, 68, 285.
} 
an intense awareness of everything...I'm experiencing everything fully, completely, thoroughly... ${ }^{21}$

On the basis of the above description, moods (as occurrent experiential states with a first-personal phenomenology) arguably have intentional content, given that one central part of this description relates to 'the world' being presented under specific determinations ('as beautiful', or 'as good'). So, while the mood experience does not have a particular object, for example a concrete physical particular, there is nonetheless arguably an intentional experiential content, which partly captures how things seem to the subject. Philosophers have expressed this idea as follows: in moods, the 'world as a whole' is presented in a certain way; moods are 'global' and 'diffuse'. ${ }^{22}$ The idea that the 'whole world' is presented would need clarifying, perhaps the following formulation is more precise: the 'object' of a mood is the subject's total environment presented in a specific evaluative light. ${ }^{23}$ However, it should be clear that construing moods as having intentional content is a credible position.

(A3) The states have an aspectual shape. VPE, EE, and PE present what they do-the Economics sign, the gorilla, the bodily state, and in the mood case 'the world' - under certain aspects, or as having certain determinations and not others. In VPE, the Economics sign is seen as purple and rectangular; in EE, the gorilla is experienced as dangerous; in PE, the bodily state is experienced as 'bad-for-one' or (more determinately) as agonizing; in joy, the 'whole world' is experienced as imbued with positive value. Experiences with intentional content of the kind we are considering therefore present their objects in certain ways, as being 'thus and so'. ${ }^{24}$

(A4) A change in experiential intentional content changes phenomenal character. Given the kind of content the experiences have is intentional experiential content, then a change in content, and so a change in how the experience presents its object, would change the phenomenal character. For example, in VPE, if the Economics sign was seen as phenomenally-blue rather than phenomenally-purple there would be a phenomenological difference: what-it-is-like-for me to see the Economics sign as phenomenally-blue is different from what-it-is-for-me to see it as phenomenallypurple. ${ }^{25}$ Likewise, in EE, if the gorilla did not strike me as dangerous, but as harmless, there would be a phenomenological difference. And finally, in PE, if the bodily state did not seem bad-for-me, but good-for-me, then there would be a phenomenological difference. So, intentional experiential content constrains overall phenomenal character.

(A5) Similar rationalizing roles. Arguably in the cases we are considering the relevant content can be cognitively significant, by contributing to the subject's reason for judging that the relevant object is thus and so. More specifically, it can ground a (non-inferential) rational transition from experience to judgement, in which the

\footnotetext{
21 This is an assemblage of descriptions of joy given in Davitz (1969: pp. 68-70).

22 See Solomon (1993: p. 17), Crane (1998: pp. 229-51), Goldie (2000: pp. 141-151) and Prinz (2004: p. 185). In the psychological literature see Marcel and Lambie (2002: p. 223).

23 See Mitchell (2018: pp. 1-18), for a defense of this kind of view.

24 See Searle (1983: Ch. 1).

25 I use phenomenally-blue to distinguish the fine-grained colour property as experienced from the linguistic colour concept BLUE.
} 
object-qualifying properties can figure in the predicative position in a proposition. For example, judging that $<$ the colour of the Economic sign is purple $>$, or that $<$ the gorilla is dangerous $>$. So, it is in virtue of the experience having the experiential intentional content it does, that the subject has the ability to make judgements which draw on that content. Moreover, the subject would typically be aware that it is their intentional experience which grounds that transition from experience to judgement-there is a personal level awareness of what seems like legitimate grounds for a rational transition. ${ }^{26}$ This contrasts with blindsight and blind(affective)feel where subjects make correct judgements a numerically significant amount of times without any awareness of their rational grounds for doing so. ${ }^{27}$

(A6) The states have non-doxastic content. VPE, EE, and PE have a kind of content which is different from that which figures in symbolically mediated judgements. How best to capture this difference is difficult, although talk of non-doxastic content is one option. For example, consider that beliefs and judgements have propositions, as what follows that-clauses, as contents in a strong sense, as paradigmatically associated with expression in terms of linguistic symbols. And while we may approximate the intentional content of an intentional experience by specifying it in propositional form (e.g. I see that the Economics sign is purple) we should not overlook the difference between the manifest content of those experiences and that of linguistically structured propositional attitudes. Talk of non-doxastic content keeps this distinction in mind (if someone prefers a different term that is fine).

Talk of non-doxastic content is preferable to non-conceptual content, since different sides of the debate over whether personal level intentional content is conceptual (i.e. involves the deployment of specific conceptual capacities) will agree there is a difference between the manifest content of sense-perceptual experience (and putatively affective experience) and non-experiential content as it figures in symbolically mediated judgements. Moreover, even if one were to think that there is a distinctive kind of experiential content doxastic states have, for example a cognitive phenomenology attendant to entertaining judgements with contents that are symbolically or linguistically mediated, this will be different from the experiential content characteristic of VPE, EE, and PE. ${ }^{28}$

Let me, however, note an objection to (A6). While pains, pleasures, and moods may have non-doxastic content, there is a strand of thinking which denies this as true of emotions, namely Judgementalism. According to such views to be afraid of the gorilla is, at least in part, to judge that the gorilla is dangerous; or to experience admiration for a beautiful painting, is, at least in part, to judge that painting is beautiful. Emotional experiences would, therefore, be constituted by their doxastic content. ${ }^{29}$

However, Judgementalism is out of favour. One worry is that subjects can sincerely assent to the relevant evaluative judgement without undergoing the corresponding

\footnotetext{
${ }^{26}$ Conceptualists like McDowell (1994) and Brewer (1999) claim mental content can only be cognitively significant in this way if the relevant experience-typically sense-perceptual experience-involves the deployment of conceptual capacities (cf. Peacocke 2001: pp. 239-64).

27 On blindfeel see Berridge and Winkielman (2003: pp. 181-211).

28 See Pitt (2004: pp. 1-36) on cognitive phenomenology.

29 See Nussbaum (2001) and Solomon (1993). I thank an anonymous referee at Synthese for pressing this point.
} 
emotion, which suggests that such judgements are not sufficient for emotional experience. However, a more pertinent issue given our context is the following. Consider the Müller-Lyer illusion: one can enjoy a visual experience of the lines as different lengths, whilst simultaneously judging that this is not the case (i.e. that the sticks are in fact the same length). Generalizing, one judges that the object, as presented in experience, is not as the experience presents it as being, but nonetheless, the visual illusion persists in the face of such a judgment. Yet, in such cases, one is not thereby flouting the rational norms attendant to entertaining contradictory judgements with contradictory contents (e.g. one is not rationally required to abandon or revise one's judgement or perception). One explanation of this is that sense-perceptual experience is not necessarily constituted by doxastic content.

With the above in mind, consider recalcitrant or phobic emotions. In such cases a subject can continue to undergo an experience of fear, say, which presents the object as dangerous, whilst simultaneously, and sincerely, judging that the object does not possess the relevant evaluative property, say judging that the gorilla is not dangerous. In this respect, the emotional experience is recalcitrant with respect to one's 'better judgement' - it persists in the face of a judgment contradicting its content. Yet, in supposed analogy with sense-perceptual illusion, there seems to be a difference between the kind, or severity, of irrationality at work when someone's emotional experiences are not in line with their better judgement and when someone is entertaining directly conflicting doxastic contents. ${ }^{30}$ As in the visual case, this suggests, pace judgementalism, that emotional experiences are not necessarily constituted by doxastic content. So (A6) is in reasonably good shape.

On the basis of these six analogies is there sufficient motivation for modelling our understanding of the intentionality of affective experiences on perceptual experiences, and thinking of affective experiences as perceptual experiences, as perceptualism does?

Let's first note an advantage of the view. In claiming affective experience is representational in a way that is perceptual (and broadly analogous to sense-perception), we can claim that many affective states have correctness conditions and so truth-evaluable contents. ${ }^{31}$ If, for example, an affective experience represents an object as having an evaluative property, then we can ask whether the experience is veridical. However, while this may be a benefit of perceptualism over non-intentional alternatives-if we find it plausible that affective experiences have truth-evaluable contents - this is not necessarily tied to the claim that affective experience is perceptual or perception-like. The attribution of intentional content to any mental state involves the specification of correctness conditions, and non-perceptual intentional states have truth-evaluable contents- they represent their truth conditions, as it is sometimes put (e.g. the belief that snow is white is true iff snow really is white).

The defender of perceptualism, however, might claim that the modelling of the intentionality of affective experience on perception is justified, given the interest in truth-evaluable content that is experiential, since perceptual experience is the paradigmatic example of truth-evaluable intentional content in this sense. So, while

\footnotetext{
30 The analogy between emotional recalcitrance and perceptual illusion has been contested (see Helm 2001; cf. Döring 2014: pp. 124-36).

31 Perceptualist accounts of emotions point to correctness conditions as a motivation (see Tappolet 2016: Ch. 1).
} 
truth-evaluable content is not tied to perceptual experience per se, truth-evaluable experiential content, of a non-doxastic kind, and which can be cognitively significant in rational transitions from experience to judgement, is. So perceptualism looks in good shape given (A1)-(A6). In the next sub-section, I consider disanalogies which undermine the view.

\subsection{Disanalogies}

(D1) EE and PE involve an affective response, whereas VPE does not. One contrast between the candidate experiences is that affective experiences include being consciously moved by something, as a personal level affective response to the object of the experience, and its properties. Note this notion of 'affective response' is not merely the idea of one's affective experience being caused, but intelligibly motivated by the way the object seems, where this can be explicated in terms of the relevant psychological attitudes and being motivated to act (see below).

However, consider the following objection. Say there really is a purple and rectangular Economics sign in my sense-perceptible environment. My visual system extracts that information, 'responding' to it in this sense, and makes that information available through experience. So, my visual system is 'affected' - in one sense of that word-by an object which it picks up on. Yet, regardless of the details of how my visual system is affected in this way, this affection is different from that which I am highlighting in the case of affective experience. In VPE I do not enjoy a personal level awareness of being consciously moved. Contrastingly, in affective experience affectivity has a different character. Consider the emotional experience: the gorilla affects me in a way that provokes a personal level affective response, which we might (partly) think of in terms of a kind of psychological attitude or comportment towards the object and its properties, which also includes context-specific motivations to act (although being affectively moved in this way should not be simply equated with the relevant action-tendencies provoked by the object).

To further see the difference, consider a situation in which the gorilla is loping around, but this provokes no change in my affective attitude toward it, say because I do not notice the cage door is open. The gorilla's presence 'affects' me in the different sense-it is registered by sense-perceptual systems and this affection reaches the threshold for phenomenal consciousness-but there is a different component in play when the object (and its properties) precipitates a personal level affective response. ${ }^{32}$ While a detailed explication of this dimension will have to wait until Sect. 4, we might tentatively say the following: there seems to be a distinctive conscious, attitudinal component to affective experience which isn't present in VPE, and is importantly connected to the way in which I am made aware of the object, including its properties and features.

(D2) Affective experience violates the transparency thesis whereas VPE does not. The transparency thesis (hereafter just transparency) can be expressed as follows. When we introspectively focus on experience itself, so to speak, rather than what that experience is directed toward, we arguably find nothing to attend to but the (apparent)

\footnotetext{
32 See Müller (2017: pp. 281-308) for one way of developing this point in the case of emotions.
} 
object and its properties. In attending to experience, we seem to see right through it to the objects (apparently) outside, including their features or properties. Consider introspectively attending to VPE, as a visual experience of a rectangular and purple Economics sign. According to some philosophers, the only properties that will be salient - the only properties that capture how things are experientially for me-are properties of the (apparent) external object, that is purpleness and being rectangular as presented properties of the sign, not any 'intrinsic' properties of the experience. ${ }^{33}$

This strong version of transparency is, however, contentious. Nonetheless, even if one thinks that introspective attention to intentional experience can reveal putative nonobject involving properties of experience, it paradigmatically also involves attention to the object of the experience and its properties. ${ }^{34}$ So, we might distinguish strong and weak versions of transparency: the weak version claims introspective attention to perceptual experience, as disclosing its phenomenal character, would mostly point to (apparent) properties of the object. It seems reasonable to hold that VPE, as a paradigmatic sense-perceptual experience, will satisfy a strong or weak version of transparency (depending on the deliverances of introspection).

Affective experience, however, contravenes transparency in a distinctive way. First, the claim is not that when introspecting affective experience the relevant properties (e.g. dangerousness, or badness) seem to be properties of the experience rather than of the object. Neither is the claim that affective experience includes non-intentional qualities or accompaniments (e.g. bodily feelings or hedonic raw feels) that are not plausibly part of the intentional content of those states. ${ }^{35}$ This latter possibility is compatible with weak versions of transparency.

The issue is rather that affective experience seems to include (as D1 suggested) affective attitudes, as phenomenologically salient conscious components, which serve as the means through which one is presented with the relevant evaluative properties. Let me explain. In EE, my being psychologically affected (again 'consciously moved') seems to acquaint me with the dangerousness of the gorilla ${ }^{36}$; and in PE my being psychologically affected seems to acquaint me with the bad or agonizing character of the bodily state. If this is true, then introspection attention to affective experiences should involve a reference to such psychological affective attitudes, as conscious responses to the relevant objects and their properties (i.e. my affective experience of those evaluative properties), rather than just (a) properties of the objects per se, or (b) any non-intentional properties. As such, there is arguably an attitudinal opacity constitutive of the intentionality characteristic of affective experience, which is disanalogous from any opacity that may attend to standard perceptual experiences which do not include such affective attitudes. Yet, once this point is admitted, then it begins to look

\footnotetext{
33 See Tye (1995: p. 30), Harman (1990: p. 38), Shoemaker (1996: pp. 100, 132, 257) and Martin (2002: pp. 380-8).

34 See Siewert (2003: 35) for this point. For authors who reject (at least the strong) transparency thesis as true of sense-perceptual experience see Block (1996: pp. 19-49, 2003: pp. 165-200) and Kind (2003: pp. 225-244).

35 Deonna and Teroni (2012: pp. 68-9) and Mikko Salmela (2011: p. 25) think emotional experiences contravene transparency in this way; they claim introspective attention to the emotional experiences normally focuses on bodily feelings as putative properties of the experience not the object of experience.

36 See Goldie (2000) and Montague (2009: pp. 171-92) for similar claims for emotions.
} 
like the nature of the intentionality of sense-perceptual and affective experience- - the way these experiences present the properties they do-may be disanalogous.

Of course, we need to know more about such affective attitudes and their supposed role in presenting value (Sect. 4 provides that), but note that they are not the emotions or pains per se. Rather they seem to be a distinctive component of those experiences, which serves to present value properties of the relevant objects, as a phenomenologically salient 'intentional mode' of the experience.

Could it not, however, be responded that perceptual experience includes, as characterizing its phenomenal character, the relevant intentional modes. For example, consider roughness felt versus roughness seen, or squareness felt versus squareness seen. In such cases, we putatively have the same intentional content but there is a phenomenological difference (a phenomenal contrast). Arguably, what explains the contrast is that the experiences are in phenomenologically salient different intentional modes, qua a difference between tactually feeling roughness (or squareness) and seeing roughness (or squareness). ${ }^{37}$ Such a position is, however, contentious, not least because one can argue that roughness, for example, isn't really ever seen, and is only a proper sensible of touch. Likewise, squareness isn't ever touched and is only a proper sensible of vision. Therefore, neither properties are common sensibles, and so the content isn't the same. As such a difference in content can be enlisted to explain the phenomenal contrast, such that we don't need to appeal to phenomenologically salient perceptual modes. ${ }^{38}$ These are complex issues, but arguably perceptual experience is typically mode transparent: intentional mode qua intentional mode is not a manifest part of their phenomenal character. However, if the above analysis is along the right lines then that is not the case for affective experience.

Finally, let me consider another objection to this purported disanalogy. Even if we accept that some version of transparency (strong or weak) is true of sense-perceptual experience, arguably it fails to be so when the relevant perceptual content is so-called high-level (or 'rich') content, such as seeing something as a computer. The thought is that introspective attention to seeing a computer, reveals that the perceptual experience is dependent on a low-level visual experience of shape and colour (as a 'cognitive base' state), and as such there isn't a property of 'computerishness' to focus on, but just those shape and colour properties. If the evaluative properties which figure in the content of affective experience are, likewise, high-level contents, then a similar claim would carry over. For example, in fear, we wouldn't focus on the dangerousness of the gorilla, but its sharp teeth, aggressive posture, etc. As such these cases would be analogous qua transparency. 39

However, regardless of whether evaluative properties are best construed as highlevel in this sense, nothing that has been said above undermines the disanalogy vis-à-vis

\footnotetext{
37 See Crane (2001: p. 86) for this kind of view.

38 See Dretske (1999: p. 458). It is also worth noting that a view of sense-perceptual experience as including phenomenologically salient intentional modes would likely abandon the representationalist framework that has often motivated adherents of the strong transparency thesis. This is because if the phenomenal character of those experiences was not entirely determined by their intentional content, then a successful reduction of that phenomenal character to a specific kind of representational content, as envisioned by strong representationalism, seems less likely.

39 I thank an anonymous referee at Synthese for raising this point.
} 
the affective case involving affective attitudes as a response to the way the object seems. Say, for sake of argument, that when I introspectively attend to fear I don't focus on dangerousness, but on the relevant natural properties. I am still affectively responding to precisely those features in such a way that they precipitate my 'being moved'. So, introspective attention would still also highlight the purported means by which I am presented with those properties as mattering for me, or as being significant for me, and this would involve reference to affective attitudes. Nothing analogous is required in high-level perception. So, the disanalogy arguably stands.

(D3) Sense-perceptual experience is tied to a specific sensory modality-it is modal-whereas affective experience is non-sensory or amodal. Another contrast between affective experience and specifically sense-perceptual experience is that the latter, but not the former, is tied to specific sense-organs: eyes for visual-perception, ears for auditory perception, extremities for tactile-perception, tongue for gustatoryperception, and nose for olfactory-perception. Sense-perceptual experience typically combines these, providing a rich multi-modal experience, for example, vision and audition are often intertwined. ${ }^{40}$ Contrastingly, there are no dedicated organs for affective experiences, whether for pains, pleasures, moods or emotions. ${ }^{41}$

The defender of perceptualism may respond that this while this may be plausible for some cases of affective experience-for example, emotional experiences generated by an initial perceptual episode (like the case of seeing the open cage door which precipitates fear) which have a phenomenal character which is independent of whatever cognitive base may have initiated them-this does not show all cases of affect are amodal. Arguably some affective states are directly tied to the modality in which they occur. For example, disgusting odours are arguably affect-laden in a way not found in any other modality. However, this can be contested: arguably the disgust one registers when seeing rotten food, or touching something slimy, shows that the affective component of disgust is not essentially tied to a specific sense-modality. Furthermore, given we can have a variety of perceptual experiences that are not affect-laden, we need some explanation of what being affect-laden amounts to, especially given affective experience can be amodal. So, perhaps the weaker claim is that whereas sense-perceptual experience is tied to a specific sensory modality - it is modal-affective experience can be non-sensory or amodal; it is not essentially tied to any specific perceptual modality. ${ }^{42}$ Although more needs to be said on this issue.

(D4) Affective experience is essentially valenced whereas VPE isn't. Valence broadly refers to positive or negative charge, yet how to precisely capture this aspect of affective experience is difficult (see Sect. 4). Sufficed to say for now that affective experiences, taken as a whole, are phenomenologically valenced. For example, being afraid of the dangerous gorilla can be characterized as a negatively charged experience, in contrast to a positive one. Moreover, the property the experience represents

\footnotetext{
40 There are those who think that perception is irreducibly inter-modal (see O'Callaghan 2015). But even if this were the case, affective experience doesn't seem irreducibly inter-modal.

41 Deonna and Teroni 2012: p. 68 make this point in the case of emotions, although they do not consider potential lines of response from the defender of perceptualism.

42 See Carruthers (2018: p. 7) for a similar claim.
} 
is also valenced-danger or fearsomeness, as a property, is negative. ${ }^{43}$ Likewise, pain experience can be characterized as a negatively charged experience, in contrast to a bodily pleasure, and the property it putatively represents is also valenced-'badnessfor-one', as a property, is negative. Finally, a mood of joie de vivre is a positively charged experience, in which 'the world' is presented as being imbued with positive value. Note, these claims are compatible with the existence of ambivalent affective states (e.g. a mood of melancholy or nostalgia for a particular time in one's childhood), which may be positive in one respect and negative in a different one.

Contrastingly, VPE does not involve valence in either sense; visual-perceptual experience as a whole is not experienced as positive or negative, and the properties it represents are neither negative nor positive. Of course, perceptual experience can become valenced, for example, when one has a negative affective response to a horrible smell, or when one sees an emotionally-charged image — but it is not essentially valenced. ${ }^{44}$ Also, beyond sense-perceptual experiences, valence is not an essential feature. For example, if there are perceptions of universals, or meanings and requirements, these are paradigmatically not valenced.

Let me note, however, one example which undermines (D4), namely surprise. One response here is to claim that surprise covers two distinct emotion-types, which when it comes to episodic emotional experiences, are either positively or negatively valenced; (1) positive surprise, for example, getting a job I stood no chance of getting, and (2) negative surprise, not even making the short-list for a job I was a shoe-in for. If, however, there are valence-neutral surprises - say being surprised that one's keys are not where one left them - this will not be an option. However, in such cases it is questionable whether we still have an affective experience; perhaps such cases are intellectual intuitions or judgements about the unexpected nature of events. In any case, surprise is a reasonably exceptional case, and so doesn't undermine the general plausibility of (D4).

On this issue, however, a defender of perceptualism might respond that the primary valence of affect which their account is concerned to capture is to be understood in terms of affective experiences perceptually representing valenced evaluative properties. For example, for perceptualism the relevant negative valence of pain can be specified in terms of its representing the relevant bodily state as 'bad-for-one'. There may be additional valenced components to affective experience (e.g. motivations, hedonic tones), but these have nothing to do with the representation of value. If that is the case, then the purported disanalogy can just be explained in terms of the relevant valence of the evaluative properties that affective experiences supposedly perceptually represent. ${ }^{45}$

There are, however, two central problems with this response. First, it is possible to be in a state which represents valenced evaluative properties and yet that state not be experientially valenced. For example, one can judge that a bodily state is 'bad-for-one'

\footnotetext{
43 Neither sense of valence involves positing valenced hedonic feels as non-intentional feelings of psleasure or displeasure (cf. Aydede and Fulkerson 2014: pp. 175-198).

44 One might think smells are necessarily valenced. However, this is empirically questionable. Olfactory neutrality can arguably be achieved by the production of a so-called 'white smell' (see Weiss et al 2012: pp. 1-6).

45 I thank an anonymous referee at Synthese for raising this.
} 
(negative valence), with no attendant experiential negativity. If non-perceptual states, such as judgements, can represent valenced evaluative properties without attendant experiential valence then we need a non-question begging further explanation why perceptually represented value gains this experiential valence (i.e. not just because it is perceptually represented). ${ }^{46}$ Second, as we saw when considering (D1) and (D2) arguably the means by which affective experience presents evaluative properties is on the basis of affective attitudes. If it is plausible that such affective attitudes are valenced components of affective experience, as I argue in Sect. 4, then there is an important sense in which affective experiences are valenced that concerns their representation of value, but it is not entirely captured in terms of affective experience representing valenced evaluative properties.

(D5) Perceptual experience requires seeming perceptually present objects; senseperceptual experience satisfies this whereas affective experience need not. Arguably one necessary condition on somethings being a perceptual experience is the seeming presence of a perceptible (typically sense-perceptual) object. The 'seeming' caveat allows for subjectively indistinguishable perceptual illusions and hallucinations. The contrast between perceptual experience and affective experience is stark on this point. Affective experiences can be directed towards past and future objects, and otherwise not even seemingly perceptually present particular objects (e.g. imagined or fictional events precipitating emotions, or an imagined cut precipitating an aversive 'wincing' reaction); perceptual presence is not a requirement on enjoying an affective experience. However, it arguably makes no sense to talk of seeing, hearing, touching smelling, something one is not at least seemingly in the perceptual presence of. Arguably we miss something important about affective experience if we fail to note this disanalogy. ${ }^{47}$

\subsection{Sum of section}

While some of these disanalogies may be contested, taken together they point to significant differences between affective and perceptual experience-especially (D1), (D2) and (D4). ${ }^{48}$ More precisely, they suggest that the way in which perception and affect represent the properties they do is different, such that there might be a type of affective representation, distinct to affective experiences. If that is the case, then we should question whether the intentionality of affective experience can really be modelled, as perceptualism claims, on perceptual experience. What is arguably required is a theory which can further substantiate, and unify, the distinctive features of affective

\footnotetext{
46 This problem is discussed in the pain literature under the heading of the 'messenger-shooting objection', as an objection to Evaluativist views (see Jacobson 2013: pp. 509-19). See Mitchell (2019a: pp. 1-25), for further discussion.

47 Perhaps there are odd cases such as opening one's eyes in a pitch-dark room, in which one doesn't seem to see anything. Arguably if the subject literally cannot see anything (even just faint outlines or dark patches) this doesn't count as an instance of visual experience (it might be in the relevant respects phenomenologically indistinguishable from an episode of visual blindness).

48 These disanalogies are not exhaustive. Additionally, affective experiences are reason-based; one is afraid because the dog is dangerous. Contrastingly perceptual experiences are not normative in this sense. For a perspicuous development on this point in the case of emotional experiences, along with a discussion of other disanalogies, see Brady (2013: Ch. 3).
} 
experiences as clarifying what this supposed distinctive type of representation might amount to. The next section outlines one such theory.

\section{Affective representation}

The previous section started with specific cases, providing reflections on them; here I start with the theory, explain it in detail, contrast it with existing forms of evaluativism about affect, and then elucidate it with reference to cases.

Affective Attitude Theory: affective representation - that is the kind of representation characteristic of affective experiences - is a non-transparent and non-sensory form of evaluative representation. Across cases of affective experience, there is a felt valenced attitude (the vehicle) which represents the intentional object of the experience as minimally good or bad (the content), and one experiences that value as having the power to causally motivate the relevant felt valenced attitude.

Key features of AAT reflect the disanalogies considered in the previous section. Pulling those together and articulating the resulting picture is the next step.

\subsection{Felt valenced attitudes}

We can start by explaining the nature and role of felt valenced attitudes. One way to capture the affective response dimension of affective experiences is to posit an affective attitude which one takes towards the intentional object of the experience (evaluatively qualified).

There are a range of cognate, two-pair, (bi)valenced affective attitude terms which capture, across a range of cases, this response dimension. Here is a by no means exhaustive list: approval/disapproval, reject/accept, attraction/repulsion, like/dislike, avowal/disavowal, approach/retreat, affirm/deny, toward/away. Some of these fit the response dimension of certain affective experiences better than others. For example, while felt disapproval is a good candidate in the case of emotions like indignation or offense, it does not sound right for pain (avoidance or dislike fits better). Alternatively, while attraction, or liking, is a good candidate in the case of aesthetic admiration and amusement (one likes a funny joke), attraction does not sound quite right for bodily pleasures. Nevertheless, what is common across a range of affective experiences is an occurrent affective-attitudinal response, as part of the experience, which is valenced and, according to AAT, intentional. So, at a general level, such experiences involve positively or negatively charged feelings as attitudes of favour or disfavour.

To forestall misunderstanding the 'of' in 'feelings of favour or disfavor' is that of specification, not intentionality. The feelings of favour or disfavor are what is doing the representing (the vehicles), and are not, in first-order affective experience, objects of representation (i.e. not part of the content). ${ }^{49}$ Moreover, these valenced attitudes being felt emphasizes that they make a phenomenal difference to the experience,

49 Cf. Montague (2009, pp. 171-92) on 'self-presenting' affective phenomenology. 
such that if one were to subtract them the experience would cease to be affective in the relevant sense (this point is developed in Sect. 4.3). Finally, these felt valenced attitudes are intentional, monadic and value-representing: they target a particular object under an evaluative determination, as minimally good or bad, rather than being preferences expressible by way of comparative attitudes (i.e. favouring $\mathrm{x}$ over $\mathrm{y}$ ). So, the idea of felt valenced intentional attitudes captures the way affective intentional states represent the value of the object of the experience on the basis of their affective response dimension. This is what is principally meant by affective representation as understood here, that is a first-order representation on the basis of, or through, affect, as the way AAT intentionalizes affect. AAT, therefore, contrasts with second-order intentional views, where the relevant intentional attitude (usually a conative attitude) is directed at the experience, rather than the (non-mental) object. ${ }^{50}$

Expanding on the above ideas, we can note that positing felt valenced attitudes as playing this personal level value-representing role allows us to capture, in a philosophically precise way, a folk psychological understanding of valence. A folk psychological understanding of experiential valence approximates to a felt conscious orientation, as a charged felt comportment which connects us with, and makes us aware of, features of things which seem meaningful and significant for us - as an affective uptake of their evaluative significance. ${ }^{51}$

AAT articulates how we should think about experiential valence - the 'affective uptake' of the significance of the object-more precisely. Felt valenced attitudes, which affectively register value properties, serve as experiential correspondences for matters of value. ${ }^{52}$ Building on this, AAT explains the way object-valence (the object seeming good or bad) and attitude-valence (my attitude towards it) relate in first-order affective experiences. In broad terms, that which seems bad-negative object-valence-is affectively represented as such through a negative feeling of disfavor towards it - negative attitude-valence-as an experiential correspondence of this negative evaluative standing (ditto for the positive case). Importantly we won't get valence mismatches here, because of the tight connection between the valence of the relevant value property of the object and the valence of the attitude toward it, which presents that value. In general terms, felt favour is a response to the objects positive value, and therefore it looks to be an experiential impossibility for that positively valenced component, which picks up on and reflects the objects positive value, to be mismatched. Put otherwise, and in general terms, felt favour just is the way we pick up on positive value in affective experience (ditto for the negative case).

Before contrasting AAT with other proposals, let me say something to justify AAT taking on board the claim —of various forms of evaluativism perceptualism — that the intentional content of affective experience should be evaluatively specified. After all, the logical space admits of a position which would claim that the content of affective

\footnotetext{
50 Chris Heathwood (2007: pp. 23-44) argues pleasures should be understood as personal level de re prodesires directed at the sensory experience (see also Armstrong 1962; Brady 2018: pp. 239-250). A detailed comparison with second-order views of affect is beyond the scope of this piece; I focus on first-order evaluativist views.

51 See Charland (2007: p. 234).

52 See Marcel and Lambie (2002: p. 244).
} 
experience is non-evaluative (i.e. specified in terms of non-evaluative properties), with any evaluative dimension being attached exclusively to the attitude. ${ }^{53}$

There are a range of reasons, some of which we have already encountered, for thinking that the content of affective experience is evaluative. Let me emphasize three. (1) In our discussion in Sect. 3 (of both analogies and disanalogies) it was seen to be plausible that the first-person phenomenology of affective experience is one of the objects of those experiences seeming evaluatively qualified (e.g. in fear the relevant objects seem dangerous, in pain, bodily states seem bad or agonizing, and in joy, 'the world' seems imbued with positive value). (2) One familiar way of individuating intentional experiences is in terms of their content, and we get quite far in distinguishing different kinds of emotions, pains, pleasures, and moods in terms of a range of determinate evaluative properties as figuring in their content. (3) Many of our judgements about the objects of affective experiences apply evaluative predicates to them, an activity which would be rationally explicable if the content of those experiences involved evaluative properties in their content. These considerations are not exhaustive; however, they provide motivation for specifying the content of affective experience in evaluative terms. AAT, therefore, seeks to respects the intuition that affective experiences are essentially evaluative phenomenon by specifying their content as evaluative, albeit whilst having a distinctive story to tell on this score.

Further to this, it should also be noted that evaluative content does not become otiose on AAT due to its specification of the distinctive 'vehicle' of affective representation in terms of felt valenced attitudes. These attitudes are to be understood, and make sense as, attitudes towards values, and their felt valence (e.g. favour or disfavor) is further clarified as a response to the power of the relevant value (see Sect. 4.3). So, they would make little sense as attitudes to merely non-evaluative features of the relevant objects of affective experience. There is, therefore, an important and close connection between evaluative content and affective-attitudes according to AAT.

\subsection{Contrasting AAT with evaluativism about affect}

AAT, as outlined in the previous sub-section, differs in important ways from evaluative perceptualism. Remember, such views seek to explain the intentionality of affective experience in terms of first-order evaluative intentional content, and specify the relevant evaluative representations as perceptions - and so are committed to some form of perceptualism. ${ }^{54}$

For example, consider the perceptualist account of 'affect' provided by Robert C. Roberts. While framed primarily in terms of emotional experience, Roberts says the following: 'affect is...the way the concern-based construal feels to the person experiencing the emotion. Just as in the visual experience of a house one is appeared to in the way characteristic of house-sightings, so in fear one is appeared to...in the way characteristic of threat-confrontations. ${ }^{55}$ This is in keeping with perceptualism insofar as the relevant representations are perceptual or perception-like representations

\footnotetext{
53 See Deonna and Teroni (2015: pp. 293-311) for one such view in the emotional case.

54 See fn. 14 and 15.

55 Roberts (2003: pp. 48-9).
} 
of value, indeed Roberts claims that 'as a concern-based construal, an emotion is a perception that is 'colored' in value'. 56

On such accounts affect can just be read as affective experience, where the intentionality of such experiences is cashed out in terms of the relevant evaluative content, and valence is a matter of the supposed meaning ('positive' or 'negative') that a situation has for the subject. As such, there is no appeal to valenced attitudes as non-transparent, non-sensory forms of evaluative representation. Although, it should be noted that Roberts has a detailed proposal about the precise character of this evaluative content, as a kind of paradigm-based situational meaning structure which embeds certain counterfactual supporting concerns and care-based dispositions (e.g. to emotionally experience something as threatening that content has to embed the paradigm of something threatening that which is of value to me, and I have to perceptually construe it as such).

However, if we are to do justice to the affective dimension of the relevant phenomenology, and the way this feeds into disanalogies with perceptual experience, then such views are problematic. They fail to say enough about the relevant vehicles in terms of what we might call the 'affective paint' or the 'affective vehicle' - that is the evaluative representations themselves. Remember, we need to distinguish between vehicles (i.e. representations) — what Block calls 'mental paint', and so the vehicular properties the experience has due to what does the representing-and their intentional content (i.e. what they represent). ${ }^{57}$ Further, insofar as they do so, they arguably wrongly (given the disanalogies of Sect. 3.3) identify them with perceptual representations. AAT contrastingly posits distinctive affective-attitudes as affective representations, as the personal level 'affective vehicle' for that evaluative content. AAT is therefore distinct from evaluative perceptualism. However, this is the case not in virtue of either (1) a disagreement about the (evaluative) intentional content of affective experiences (i.e. what they represent), or (2) in being a first-order intentional view, but rather, in being a first-order affective-attitude view, which more closely reflects the phenomenology of response salient in affective experience.

Nonetheless, a critic might question how different AAT is from the view of Peter Carruthers who specifies the "valence component of any affective experience... [as a] nonconceptual representation of the goodness or badness of the object of the experience', where this view is a kind of non-perceptualist evaluative representationalism. ${ }^{58}$ On one interpretation, there is a clear difference between AAT and this proposal, since while Carruthers claims that valence is a non-sensory or amodal kind of representation-and is therefore not committed to this aspect of perceptualism-nonetheless, it looks like valence is being identified with intentional evaluative content per se. As such, in line with the discussion of evaluative perceptualism above, to undergo a valenced experience just is to enjoy an experience which represents the relevantly valenced evaluative properties, and so has the relevant evaluative content (a minimal goodness or badness of the object). So, there would be only one valence present in affective experience, namely, object valence. Yet, according to AAT, there is a distinctive personal level 'affective vehicle' — a felt valenced attitude—which serves as the

\footnotetext{
56 Ibid: pp. 48-9.

57 See Block (1996: pp. 19-49).

58 Carruthers (Carruthers 2018: p. 7).
} 
carrier of evaluative content, and arguably there needs to be to capture the affective phenomenology of response to value, and the non-transparency of affective experience.

To re-emphasize then, AAT is a first-order affective-attitude view, and so specifies two types of valence as present in affective experience, namely object-valence and attitude-valence. Carruthers arguably comes closer to this position when he says, 'when one imagines the colonoscopy and feels anxious, the negative valence thereby produced represents the colonoscopy as (nonconceptually) bad' ${ }^{59}$ Here Carruthers ostensibly distinguishes (1) the valenced representation (negative valence as a personal level vehicle) and (2) the valenced intentional content (colonoscopy as bad). If this is his considered view then it is structurally similar to AAT. Although it bears noting that Carruthers does not mention any affective attitudes, as purporting to capture this valenced representation of value. AAT seeks to cash this out in terms of felt valenced attitudes, and so could be seen as a more detailed proposal concerning how to think about a valenced representation of value, where we distinguish between the valenced representation and the valenced intentional content it takes up.

Let me now note a respect in which AAT might be thought preferable to both evaluative perceptualism and (non-perceptual) evaluative representationalism (i.e. Carruthers on the first reading). By positing felt valenced attitudes as the valuerepresenting aspect of affective experiences we get one answer to the following question concerning motivation. What feature do pains, pleasures, moods, and emotions have in common which strongly ties them to motivating behaviour, which paradigmatic cognitions and perceptions lack? It has often been noted that affective experiences inherently motivate behaviour, yet why would that be so? Given AAT we have the outline of an answer: in affective experiences, there is a felt valenced attitude which registers the minimal goodness or badness of the intentional object. And we know that valence, in our case specifically personal level attitude-valence, is importantly connected to motivating behaviour (it includes motivations to act). So, at a general level, a feeling of disfavor towards that which seems bad, for example, should in the relevant circumstances, and given satisfaction of the relevant background conditions, motivate general avoidance or rejection behaviour. Importantly though-and as previously noted, while felt valenced attitudes inherently motivate behaviour (certeris parabus) we should resist equating them with conative states, much less specific actions (e.g. running away).

Nonetheless, the evaluativist views considered above might respond that they can easily capture this motivational dimension; it is in virtue of the property represented, namely an evaluative property, that affective experience is motivational. ${ }^{60}$ However, this is arguably problematic. If it is plausible that we can experientially represent value in non-affective states, say in certain forms of aspectual perception or value-intuition (e.g. seeing the cliff edge as dangerous; seeing the painting as beautiful), then an experiential or perceptual representation of value will not suffice for motivation, since in such cases we need not be motivated to act (although more need to be said on this issue). The thought on the present proposal is that it the distinctive way in which affective experience represents value-namely by way of felt valenced attitudes-which

\footnotetext{
59 Ibid: p. 10.

60 I thank an anonymous referee at Synthese for raising this response.
} 
explains the tighter connection to motivation than would be the case for any experiential representation of value lacking such a component (this point is developed more in Sect. 4.3 in the claim that affective experiences present value properties as having a distinctive kind of causal power).

In sum, AAT is distinctive from, and in certain respects arguably preferable to, the evaluative perceptualist and evaluative representationalist views considered so far. ${ }^{61}$

Next, consider the relation between AAT and Bennet Helm's view of 'felt evaluations' as constitutive of affect, as a related form of affective evaluativism. Helm frames his felt evaluations as distinctive forms of 'pains' and 'pleasures'. However, they are not 'bodily sensations'. Helm writes, 'felt evaluations... are feelings of positive or negative import...thus to feel fear [for example] is to be pained by danger...danger impresses itself on one, grabbing one's attention and priming one to act' ${ }^{62}$ The difference between AAT and Helm's proposal is in its philosophical preciseness and the details of how we cash out the supposed 'experiential correspondence of significance'. For example, Helm's talk of 'feelings of evaluative content, whereby import impresses itself upon us' and being 'enthralled [by an] evaluation' is too suggestive and imprecise. ${ }^{63}$ We do not feel evaluative content per se in affective experience, and attention is directed at the object, evaluatively qualified, not the affective representation itself (i.e. the vehicle). We feel the object of experience to be a certain evaluative way on the basis of an affective response, which is a structured experience AAT specifies in terms of felt valenced attitudes, which serve as vehicles for the relevant content. So, AAT goes further into the detail of so-called 'felt evaluations', telling us more about the vehicular properties of affective representations in a way which builds on Helm's proposal, but more closely reflects the phenomenology.

Finally, I should note that for reasons of space, and given that the scope of AAT is that of affective experience generally, I have not provided a comparison with recent nonperceptual theories of emotional experience, with which it has similarities and shares some motivations. ${ }^{64}$ A substantive difference is that AAT preserves the claim that

\footnotetext{
61 A critic might ask given the tight connection to motivation, whether this first-order affective dimension, salient in affective experience, is not better construed as a first-order intrinsic desire toward the intentional object. We might characterize this in terms of a conative (desire-like) attitude or 'phen-desire' with this character (see Jacobson 2018: pp. 1-27; Aydede and Fulkerson 2014: pp. 119-33, 2019: pp. 27-59). However, the current proposal is distinct from such views and in fact there are central disanalogies with it. Favour of disfavour toward the relevant object (evaluatively qualified) - what AAT claims characterizes the attitudinal dimension of affective experience - is not identical with a conative attitude towards the relevant object. In other words, disfavour is not the same thing as wanting something to cease; and favour is not the same thing as wanting something to continue. There are also differences in the direction of fit. Conativeattitudes don't intend to match up with actualized states of affairs, rather they seek to make it such that the relevant state of affairs, which is the object of the conation, be fulfilled. They have 'world-to-attitude' direction of fit. Contrastingly, the affective-attitudes of favour and disfavour are valenced responses to states of affairs that have already obtained. So, the direction of fit seems closer to 'attitude-to-world'. Given this, felt valenced attitudes of favour and disfavour are not plausibly conative attitudes but rather sui generis affective attitudes. Although I save a more detailed comparison of AAT with first-order desire views for a separate occasion.

62 Helm (2002: p. 19).

63 Helm (2001: pp. 74 and 80-1).

64 See particularly Deonna and Teroni (2015: pp. 293-311) (see Müller 2017: pp. 281-308 for some worries about this view).
} 
affective experiences have evaluative content. Furthermore the relevant felt valenced attitudes posited by AAT are not bodily attitudes towards (non-evaluative) contents in the way developed by Julien Deonna and Fabrice Teroni. Whatever the promise of such a view in the emotional case, it is not clear how it could be applied to moods, pains or pleasures without significant revision. Insofar as it is desirable to have a general theory of affective experience, on which important differences within the affective domain can be then charted out, then AAT fits this role.

The next section specifies the second dimension of AAT, concerning the power of values to causally motivate affectivity, a detailed explication of which is not found in the any of first-order evaluativist views considered so far.

\subsection{Values as having the power to causally motivate affectivity}

The second dimension of AAT is the claim one experiences the relevant goodness or badness as causally motivating the relevant felt valenced attitude. To forestall confusion, the claim is not that there are two representations, one which represents the intentional object as minimally good or bad, and a separate one which represents goodness or badness as having the power to causally motivate the affective attitudes. Nor is the claim that there is a doxastic state about the causal power of the relevant value. Rather, the idea is that the way values are experienced is as having the power to causally motivate the affectivity they do. Clearly explaining this dimension is difficult. First I explain it via direction of fit versus direction of causation, and then with reference to cases.

Given what was said about the way felt valenced attitudes represent value they have an intentional direction of fit which is attitude-to-object: the attitude is supposed to reflect the evaluative standing of the object (as good or bad); object-valence and attitude-valence are supposed to match up in this sense. ${ }^{65}$ However, the direction of causation is experienced as object-to-attitude: it is the objects evaluative standing which is experienced as having the power to motivate the affective attitude it does, which we experience insofar as we are moved by it.

To further explain this claim, and its significance, I consider two cases in which the felt valenced attitudes are missing and contrast them with normal cases. First, consider the case of fear, absent the relevant felt valenced attitude. If, in an experience of fear, we subtract the strong feeling of disfavor towards the object (including the avoidance behavior consequent on it), what would be left? Perhaps, as attested by people with specific kinds of neurological damage-Antonio Damasio's Phineas Gage style cases ${ }^{66}$ - there would be an intellectual appreciation of the object of one's experience as bad (or dangerous), but no affective appreciation of the danger. Yet what does affective appreciation of badness or danger amount to? We need to say more about how lacking the relevant affective attitudes impacts on the experience of those objects' evaluative significance.

In everyday fear-in contrast to the subject who intellectually appreciates fear but does not 'feel fear' due to neurological damage - the difference cannot be fully

65 On direction of fit and direction of causation see Searle (1983: Ch. 1).

66 Damasio (1994: Ch. 2 and 3). 
captured just by saying the normal subject also has the relevant felt valenced attitude. Rather, in virtue of the ordinary affective experience involving these felt valenced attitudes it represents the object's evaluative standing differently, not only as bad per se, but being bad such as to involve an experience of a power to immediately and intelligibly causally motivate strong feelings of disfavor towards it. When felt valenced attitudes go missing, and so when affective representation drops out of the picture, evaluative properties lose that affective power. ${ }^{67}$

To further see this, consider the case of ordinary pain experience contrasted with pain asymbolia, either as congenital insensitivity to pain or pain anesthesia (specifically morphine analgesia). Ordinary pain experience, which is paradigmatically felt, valenced — negatively in all but masochistic cases — and experienced as involving a response, is said by current first-order evaluativist views to represent a non-mental bodily state (usually located at a specific place) as bad-for-one. ${ }^{68}$ According to AAT though, this is only part of the story. At the personal level, affective representation in unpleasant pain experience is arguably as follows: there is as an (interoceptive) affective registering of a specific bodily state as $b a d$, such that the felt valenced response of strong disfavour (the vehicle) represents that bodily state as bad (the content).

Contrast the above with cases of pain asymbolia. What is going on, at the personal level, in cases where subjects attest to registering the relevant bodily state but claim not to care - they report that it does not bother them? Again, one explanation is that they lack the relevant valenced affective-attitudinal component, that strong disfavor towards the bodily sensation, which AAT specifies as an essential feature of paradigmatic pain experience. This seems correct, but again misses out an essential dimension of the story, which AAT emphasizes.

Consider the case of subject-P who has never experienced an ordinary unpleasant pain. $\mathrm{P}$ is taught, through cognitive learning processes, to think of these bodily sensations as bad. Medical professionals and psychologists inform $\mathrm{P}$ that they typically lead to, or indicate, various kind of bodily damage or pathology, that she should avoid, for everyday pragmatic reasons, and for broader survival reasons - she understands the externalist psychosemantics of pain, and so what pain represents in this functionalcausal sense. As part of this process $\mathrm{P}$ also learns the relevant avoidance and reaction behavior, including facial expressions (e.g. grimaces), and vocalizations (“Ow”!). To an external observer unaware of P's congenital pain asymbolia there would be no reason to doubt $\mathrm{P}$ was having unpleasant pain experiences. It is intuitive that even if such learning and mimicry were entirely successful, and properly internalized ( $\mathrm{P}$ would not have to make any conscious inference from the presence of a certain bodily state to taking the relevant avoidance steps) P would not be affectively acquainted, first hand, with the badness of pain as normal subjects are. But what precisely is this difference?

AAT provides the following answer: absent the relevant felt valenced attitudes, the evaluative content of the experience is significantly impoverished in that the bodily state is not experienced as affectively salient for $\mathrm{P}$ as when experienced as having the power to immediately and intelligibly causally motivate the negative felt valenced

\footnotetext{
67 For a more extended discussion of this point in the case of emotions see Mitchell (2019b: pp. 1-28).

68 See Tye (2005: pp. 99-120), Tye and Cutter (2011: pp. 90-109), and Bain (2017: pp. 462-90).
} 
attitudes (and the avoidance behavior that comes with it). That is when the bodily state is affectively represented as bad.

It has been claimed by both psychologists and philosophers that pain experience has at least two dissociable components, namely the affective/evaluative dimension and the bodily dimension. Pain asymbolia attests to personal level experiences lacking the former dimension while retaining the later. ${ }^{69}$ What has been less appreciated is that when the affective/evaluative component is lost the bodily dimension has no immediate affective salience for the subject, where AAT suggests we should understand this to signify that the bodily state lacks the power to immediately and intelligibly causally motivate affectivity - it is affectively-flat in this sense. ${ }^{70}$

Summing up, when the objects of value lose this power to immediately and intelligibly causally motivate affective attitudes, either due to neurological damage, congenital diseases, or in everyday circumstances such as loss of interest, there is no longer affective representation - that is representation of value as experientially salient in this way-values no longer move us in the immediately intelligible way they typically do.

\section{Conclusion}

My goal here was to provide a theory of affective representation in phenomenal consciousness, as growing out of disanalogies between perceptual and affective experience. One central aspect in which the theory requires further development is in providing a more detailed account of how it deals with moods and bodily pleasures if these are understood as intentional states. However, AAT — as a first-order affectiveattitude view-provides a good starting point for theorizing about the intentionality and phenomenology of affective experiences in a way which reflects their distinctive characteristics. Moreover, it is interestingly distinct from various forms of evaluativism about affect and arguably is in certain respects preferable. In any case, AAT is worth serious consideration.

Acknowledgements I would like to thank Joel Smith and Laura Gow for their comments on previous drafts. Further to this, the detailed feedback of the three anonymous reviewers at Synthese was invaluable in improving the paper. Finally, I would like thank audiences at the Open University and the University of Johannesburg for inviting me to present earlier drafts of this material. This research was, in part, supported by the British Academy.

\footnotetext{
69 See Melzack and Casey (1970: pp. 55-68). See Grahek (2007) for discussion of pain asymbolia.

70 John Searle (1983: pp. 112-40) claims that sense-perceptual experience involves a causal self-reflexivity in its content which might be thought analogous to this aspect of AAT. Yet, one worry with that claim in the perceptual case is as follows. Consider again that sense-perceptual experience is often claimed to be transparent, in that it is experienced as involving a direct, immediate non-inferential relation to the relevant object. However, if it involved a self-referential causal aspect in its content then, so the worry goes, this would obstruct the phenomenology of what at least partly seems like a direct relation to the object (see Soteriou 2000: pp. 173-189). Yet, if affective experiences are non-transparent then no such worry with causal self-reflexivity in their content is relevant. Further, the relevant causal aspect is that of a component of the experience, a valenced attitude (rather than the experience itself, as Searle seems to claim in the perceptual case), being intelligibly motivated by the objects and its properties, and there is no such normativity in play in perceptual experience.
} 
Open Access This article is distributed under the terms of the Creative Commons Attribution 4.0 International License (http://creativecommons.org/licenses/by/4.0/), which permits unrestricted use, distribution, and reproduction in any medium, provided you give appropriate credit to the original author(s) and the source, provide a link to the Creative Commons license, and indicate if changes were made.

\section{References}

Armstrong, D. M. (1962). Bodily sensations. London: Routledge.

Aydede, M., \& Fulkerson, M. (2014). Affect: Representationalists' headache. Philosophical Studies, 170, $175-198$.

Aydede, M., \& Fulkerson, M. (2019). Reasons and theories of sensory affect. In D. Bain, M. Brady \& J. Corns (Eds.), The nature of pain (pp. 27-59). London: Routledge.

Bain, D. (2003). Intentionalism and pain. Philosophical Quarterly, 52(213), 502-523.

Bain, D. (2017). Why take painkillers. Nous, 53(2), 462-490.

Barlassina, L., \& Newen, A. (2014). The role of bodily perception in emotion: In defense of an impure somatic theory. Philosophy and Phenomenological Research, 83(3), 637-678.

Berridge, C. K., \& Winkielman, P. (2003). What is an unconscious emotion? (The Case for Unconscious "Liking"). Cognition and Emotion, 17(2), 181-211.

Block, N. (1995). On a confusion about a function of consciousness. Behavioral and Brain Sciences, 18, $227-287$.

Block, N. (1996). Mental paint and mental latex. Philosophical Issues, 7, 19-49.

Block, N. (2003). Mental paint. In M. Hahn \& B. Ramberg (Eds.), Essays on the philosophy of tyler burge (pp. 165-200). Cambridge: MIT Press.

Brady, M. (2013). Emotional insight: The epistemic role of emotional experience. Oxford: Oxford University Press.

Brady, M. (2018). Painfulness, desire, and the euthyphro problem. American Philosophical Quarterly, 55(3), 239-250.

Brewer, B. (1999). Perception and reason. Oxford: Oxford University Press.

Campbell, J. (2002). Reference and consciousness. Oxford: Oxford University Press.

Carruthers, P. (2018). Valence and value. Philosophical and Phenomenological Research, 97, 658-680.

Chalmers, D. (1996). The conscious mind. Oxford: Oxford University Press.

Charland, L. C. (2007). Emotion experience and the indeterminacy of valence. In L. F. Barrett, P. M. Niedenthal, \& P. Wiinkieldman (Eds.), Emotion and consciousness. London: Guilford Press.

Crane, T. (1998). Intentionality as the mark of the mental. In A. O'Hear (Ed.), Contemporary issues in the philosophy of mind (pp. 229-251). Cambridge: Cambridge University Press.

Crane, T. (2001). Elements of mind: An introduction to the philosophy of mind. Oxford: Oxford University Press.

Damasio, A. (1994). Descartes' error: Emotion, reason and the human brain. London: Picador.

Davitz, J. R. (1969). The language of emotion. London: Academic Press.

De Sousa, R. (1987). The rationality of emotion. Cambridge: MIT Press.

Dennett, D. (1969). Content and consciousness. London: Routledge.

Deonna, J., \& Teroni, F. (2012). An introduction to the philosophy of the emotions. London: Routledge.

Deonna, J., \& Teroni, F. (2015). Emotions as attitudes. dialectica, 66(3), 293-311.

Döring, S. (2014). Why recalcitrant emotions are not irrational. In S. Roeser \& C. Todd (Eds.), Emotion and value (pp. 124-136). Oxford: Oxford University Press.

Dretske, F. (1999). Perception, knowledge and belief (pp. 158-177). Cambridge: Cambridge University Press.

Fodor, J. (1975). The language of thought. New York: Crowell.

Goldie, P. (2000). The emotions. Oxford: Oxford University Press.

Grahek, N. (2007). Feeling pain and being in pain. Cambridge: MIT Press.

Harman, G. (1990). The Intrinsic Quality of Experience. In J. E. Tomberlin (Ed.), Philosophical perspectives 4: Action theory and the philosophy of mind (pp. 31-52). Ridgeview: Atascendero, CA.

Heathwood, C. (2007). The reduction of sensory pleasure to desire. Philosophical Studies, 133(1), $23-44$. Helm, B. (2001). Emotional Reason. Cambridge: Cambridge University Press. 
Helm, B. (2002). Felt evaluations: A theory of pleasure and pain. American Philosophical Quarterly, 39, 13-30.

Hill, C. (2006). Ow! The paradox of pain. In M. Aydede (Ed.), Pain: New essays on its nature and the methodology of its study (pp. 75-98). Cambridge, MA: MIT Press.

Hill, C. (2009). Consciousness. Oxford: Oxford University Press.

Horgan, T., \& Tienson, J. (2002). The intentionality of phenomenology and the phenomenology of intentionality. In D. Chalmers (Ed.), Philosophy of mind: Classical and contemporary readings (pp. 520-533). Oxford: Oxford University Press.

Jacobson, H. (2013). Killing the messenger: Representationalism and the painfulness of pain. Philosophical Quarterly, 63(252), 509-519.

Jacobson, H. (2018). Not only a messenger: Towards an attitudinal-representational theory of pain. Philosophy and Phenomenological Research. https://doi.org/10.1111/phpr.12493.

Johnston, M. (2001). The authority of affect. Philosophy and Phenomenological Research, 63(1), 181-214.

Kind, A. (2003). What's so transparent about transparency? Philosophical Studies, 115, 225-244.

Lycan, W. (1996). Consciousness and experience. Cambridge: MIT Press.

Marcel, J. A., \& Lambie, J. A. (2002). Consciousness and the varieties of emotion experience: A theoretical framework. Psychological Review, 109(2), 219-259.

Martin, M. (2002). The transparency of experience. Mind and Language, 4(4), 376-425.

McDowell, J. (1994). Mind and world. Cambridge: Harvard University Press.

Melzack, R., \& Casey, K. L. (1970). The affective dimension of pain. In M. B. Arnold (Ed.), Feelings and emotions (pp. 55-68). New York: Academic Press.

Mitchell, J. (2018). The intentionality and intelligibility of moods. European Journal of Philosophy. https:// doi.org/10.1111/ejop.12385.

Mitchell, J. (2019a). Can evaluativism about unpleasant pains meet the normative condition? Inquiry. https:// doi.org/10.1080/0020174X.2018.1562377.

Mitchell, J. (2019b). Emotional Intentionality and the attitude-content distinction. Pacific Philosophical Quarterly. https://doi.org/10.1111/papq.12270.

Montague, M. (2009). The logic, intentionality, and phenomenology of emotion. Philosophical Studies, 145(2), 171-192.

Müller, J. M. (2017). How (Not) to think of emotions as evaluative attitudes. dialectica, 71(2), 281-308.

Nelkin, N. (1989). Unconscious sensations. Philosophical Psychology, 2, 129-141.

Nussbaum, C. N. (2001). Upheavals of thought: The intelligence of emotions. Cambridge: Cambridge University Press.

O'Callaghan, C. (2015). Not all perceptual experience is modality specific. In D. Stokes, M. Matthen \& S. Biggs (Eds.), Perception and its modalities (pp. 133-165). Oxford: Oxford University Press.

Peacocke, C. (2001). Does perception have a nonconceptual content? Journal of Philosophy, 98, 239-264.

Pitcher, G. (1970). Pain perception. The Philosophical Review, 79(3), 368-393.

Pitt, D. (2004). The phenomenology of cognition; or what is it like to think that P? Philosophy and Phenomenological Research, 69, 1-36.

Poellner, P. (2016). Phenomenology and the perceptual model of emotion. In Proceedings of the aristotelian society (vol. CXVI, Part 3: 1-28).

Prinz, J. (2004). Gut reactions: A perceptual theory of emotion. Oxford: Oxford University Press.

Roberts, R. (2003). Emotions in the moral life. Cambridge: Cambridge University Press.

Russell, J. A., \& Barrett, L. F. (1999). Core affect, prototypical emotional episodes, and other things called emotion: dissecting the elephant. Journal of Personality and Social Psychology, 76, 805-819.

Salmela, M. (2011). Can emotions be modelled on perception. dialectica, 65(1), 1-29.

Sartre, J. P. (2003). Sketch for a theory of the emotions. London: Routledge.

Scheler, M. (1973). Formalism in ethics and non-formal ethics of values (M. S. Frings, R. L. Funk, Trans). Evanston, IL: Northwestern, University Press.

Searle, J. (1983). Intentionality: An essay in the philosophy of mind. New York: Cambridge University Press.

Shoemaker, S. (1996). The first-person perspective and other essays. Cambridge: Cambridge University Press.

Siewert, C. (2003). Is experience transparent? Philosophical Studies, 117, 15-41.

Solomon, R. (1993). The passions: Emotions and the meaning of life. Indianapolis: Hackett.

Soteriou, M. (2000). The particularity of visual perception. European Journal of Philosophy, 8(2), 173-189.

Tappolet, C. (2016). Emotions, values and agency. Oxford: Oxford University Press. 
Tye, M. (1995). Ten problems of consciousness. Cambridge: MIT Press.

Tye, M. (2005). Another look at representationalism about pain. In M. Aydede (Ed.), Pain: New essays on its nature and the methodology of its study (pp. 99-120). Cambridge, MA: MIT Press.

Tye, M. (2008). The experience of emotion: An intentionalist theory. Revue Internationale de philsophie, 243, 25-50.

Tye, M., \& Cutter, B. (2011). Tracking representationalism and the painfulness of pain. Philosophical Issues, 21(1), 90-109.

Weiss, T., Snitz, K., Yablonka, A., Khan, R., Gafsou, D., Schneidman, E., \& Sobel, N. (2012). Perceptual convergence of multi-component mixtures in olfaction implies an olfactory white. In Proceedings of the national academy of sciences of the United States of America, early view. www.pnas.org/cgi/doi/ $10.1073 /$ pnas. 1208110109.

Whiting, D. (2009). The feeling theory of emotion and the object-directed emotions. European Journal of Philosophy, 19(2), 281-303.

Publisher's Note Springer Nature remains neutral with regard to jurisdictional claims in published maps and institutional affiliations. 